\title{
Sero-prevalence of Transfusion Transmissible Infections among Voluntary Blood Donors of Khulna Medical College Hospital.
}

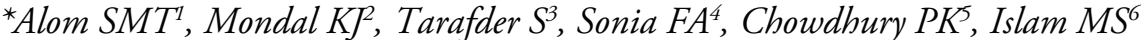

\begin{abstract}
Transfusion transmitted infections (TTI) are a great concern of safety for patients. Blood transfusion is a lifesaving procedure but always caries a potential risk of infections. The present study was designed to evaluate the prevalence of infectious disease markers and frequency in males and females of various age groups among healthy blood donors. A retrospective review of donor record over a period of 2 years between 2015 to2016 was done at the department of transfusion medicine Khulna medical college Hospital, Khulna, Bangladesh.Among the total 37,266 donors,358(0.96\%) donors were infected and therefore not suitable for blood donations. HBV was found to be the most frequent infection with a total frequency of $0.72 \%$ followed by TP (0.20\%), HCV (0.03\%) and HIV (0.01\%). None of the blood samples showed positivity for malarial parasite.Majority of the seropositive donors, (47.96\%) were in the age group of 26 to 35 years followed by $29.47 \%$ in 18 to 25 years' age group.
\end{abstract}

Key words: Transfusion Transmitted infection(TTI), Seroprevalence, Voluntary donors.

\section{INTRODUCTION}

Transfusion medicine has a great public health importance worldwide. Blood transfusion has been used since 1930 for

1. *Dr. S M Tushar Alom, MD( Microbiology), Department of Transfusion Medicine, Khulna Medical College Hospital, Khulna. Email: dr.tushar2021@gmail.com.

2. Dr. Kanak Jyoti Mondal, Registrar, Department of Medicine, Khulna Medical College Hospital, Khulna.

3. Dr. Shirin Tarafder, MPhil( Microbiology), Associate Professor, Department of Microbiology, Bangabandhu Sheikh Mujib Medical University, Dhaka

4. Dr. Farah Anjum Sonia, Medical Officer, Department of Transfusion Medicine, Bangabandhu Sheikh Mujib Medical University, Dhaka

5. Dr. Poritosh Kumar Chowdhury, Associate Professor, Department of Respiratory Medicine, Khulna Medical College Hospital, Khulna.

6. Dr. Md Shoriful Islam, Resident, Department of Nephrology, Dhaka Medical College Hospital, Dhaka

${ }^{*}$ For Correspondence various indications and the demand for blood and its components is likely to increase in the future ${ }^{1}$. In Bangladesh blood transfusion service was started in 1950 at the Dhaka Medical College Hospital. The importance of ensuring blood safety as well as the adequacy of the national blood supply is highlighted due to the emergence of HIV in the 1980. The following screening tests were performed in the blood transfusion centers: HBsAg, Syphilis, Malarial Parasite, Anti-HCV, Anti-HIV. To ensure safety, adequacy, accessibility and efficiency of blood supply at all levels, the Bangladesh Government has passed 'Safe Blood Transfusion Law 2002' in the Parliament and 'Safe Blood Transfusion Rules 2008'2. The magnitude of the TTIs varies from country to country depending on the incidence of these infections in that particular population. Majority of the problems are due to the prevalence of asymptomatic carriers in the society, as well as blood donations during the window period of infections ${ }^{3,4}$. These unsafe blood transfusions are very costly from both human and economic points of view.Hence, implementation of effective donor selection criteria and quality of screening tests are important and critical in preventing transmission of these infections. Screening for TTIs also gives clue about the prevalence of these infections in healthy populations and is the greatest challenges to transfusion medicine in developing countries 5 . This study was undertaken to see the sero-prevalence of TTI among healthy blood donors at Khulna Medical College Hospital.

\section{MATERIALS AND METHODS}

This retrospective study was conducted among healthy blood donors at transfusion medicine department of Khulna Medical College Hospital over a period of two years between January 2015 to December 2016. The study population constituted voluntary donors and most of the cases relatives of thepatients. Voluntary blood donors are those who donate blood without remuneration. During these period, total 37,266 subjects of both sexes, different age groups and from different nearby districts of Khulna were screened. Donors were selected by taking history, clinical examination and following strict donor selection criteria to eliminate professional donors. All the samples were screened for HBsAg, HCV, HIV 1 and 2, Syphilis and malaria parasite by rapid immunochromatographic (ICT) assay (EXCEL). 
All the positive samples were repeated 3 times before labeling as seropositive and respective blood units were discarded. All data were analyzed by MS-EXCEL 2016.

\section{RESULTS}

In the present study, a total of 37,266 units of blood were collected from the volunteer blood donors at Khulna medical college hospital, Khulna during the year 2015 and 2016. Of these, 35,081 (94.14\%) were males and 2,185(5.86\%) were females which shows predominance of males as compared to females for the two studied years (Table I).

Table I. Yearly gender wise distribution of blood donors in the present study year total samples tested males and females $(n=37,266)$.

\begin{tabular}{|c|c|c|c|}
\hline Year & Total sample tested & Males & Females \\
\hline 2015 & 18,179 & $17,177(94.49 \%)$ & $1,002(5.51 \%)$ \\
\hline 2016 & 19,087 & $17,904(93.80 \%)$ & $1183(6.20 \%)$ \\
\hline Total & 37,266 & $35,081(94.14 \%)$ & $2,185(5.86 \%)$ \\
\hline
\end{tabular}

None of the blood samples showed positivity for malarial parasite. HBV and TP were the most prevalent infections throughout the study period. Among the seropositive donors, 184 (47.96\%) were in the age group of 26 to 35 years followed by $109(29.47 \%)$ in 18 to 25 years' age group (Table-III).

\section{Frequency of TTI}

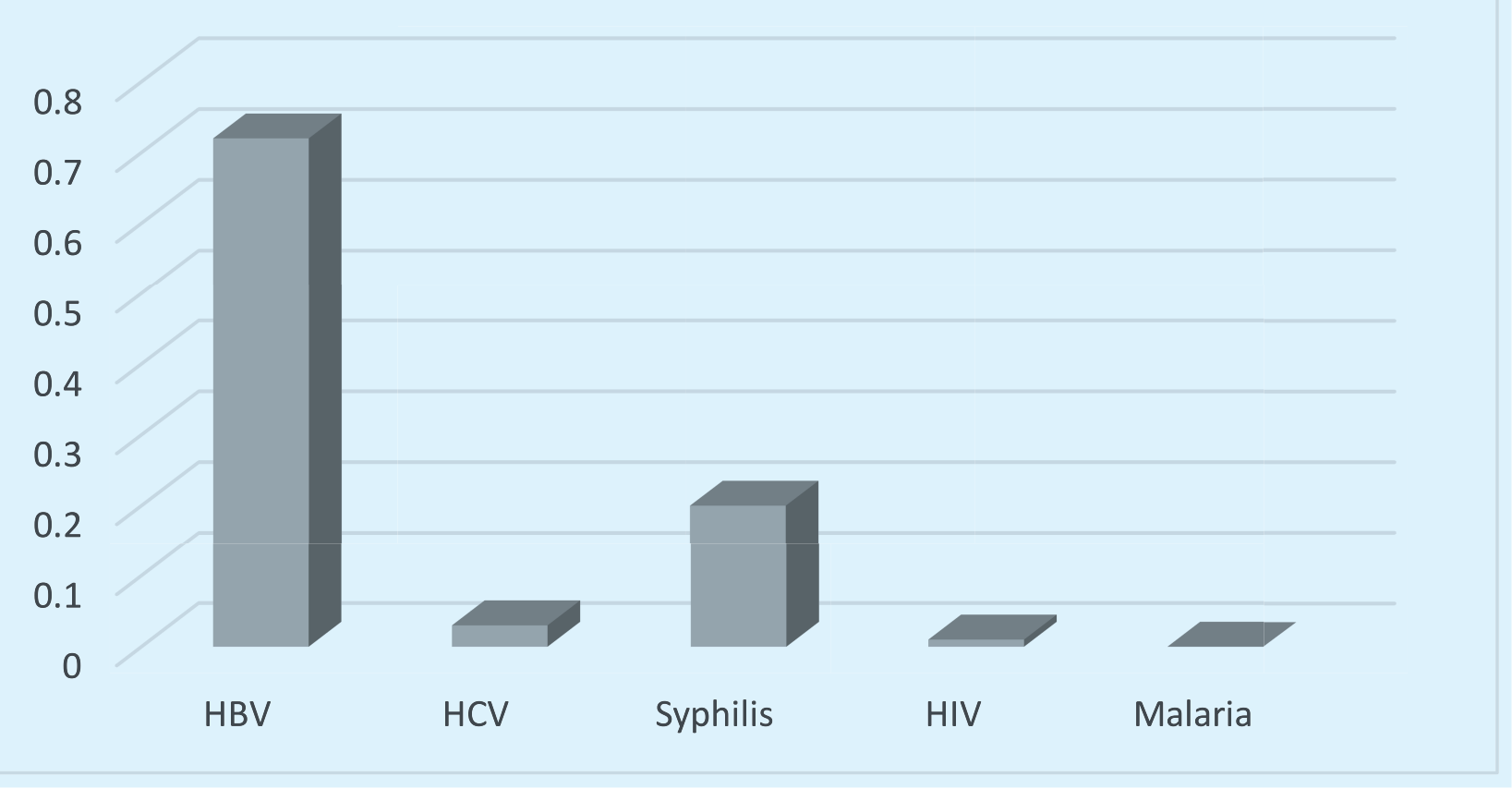

Figure-1: Frequency of transfusion transmissible infections $(n=37,266)$.

Among the total 37,266 donors, 36,908 (99.04\%) were found healthy and safe for transfusion while the remaining $358(0.96 \%)$ donors were infected and therefore not suitable for blood donations. During the study period, HBV was found to be the most frequent infection among blood donors with a total frequency of $0.72 \%$ followed by TP $(0.20 \%)$, HCV $(0.03 \%)$ and HIV $(0.01 \%)$ as shown in (TableII) 
Table II. Prevalence of HBV, HIV, HCV and Syphilis among blood donors in the present study $(n=37,266)$.

\begin{tabular}{|c|c|c|c|c|c|c|}
\hline Year & $\begin{array}{c}\text { Sample } \\
\text { tested }\end{array}$ & $\begin{array}{c}\text { Positive } \\
\text { samples(\%) }\end{array}$ & HBV(\%) & HCV(\%) & SYPHILIS(\%) & HIV(\%) \\
\hline 2015 & 18179 & $197(1.08 \%)$ & $142(0.78 \%)$ & $9(0.05 \%)$ & $46(0.25 \%)$ & 0 \\
\hline 2016 & 19,083 & $161(0.84 \%)$ & $127(0.66 \%)$ & $2(0.01 \%)$ & $30(0.16 \%)$ & $2(0.01 \%)$ \\
\hline Total & 37,266 & $358(0.96 \%)$ & $269(0.72 \%)$ & $11(0.03 \%)$ & $76(0.20 \%)$ & $2(0.01 \%)$ \\
\hline
\end{tabular}

Table III. Prevalence of transfusion transmitted infections among different age groups $(n=37,266)$.

\begin{tabular}{|c|c|c|c|c|c|}
\hline Age(Years) & $18-25(\%)$ & $26-35(\%)$ & $36-45(\%)$ & $46-55(\%)$ & Total \\
\hline HBV & $83(30.86)$ & $146(54.28)$ & $28(10.40)$ & $12(4.46)$ & 269 \\
\hline HCV & $3(27.28)$ & $5(45.45)$ & $2(18.18)$ & $1(9.09)$ & 11 \\
\hline SYPHILIS & $23(30.26)$ & $32(42.10)$ & $16(21.05)$ & $5(6.58)$ & 76 \\
\hline HIV & 0 & $1(50)$ & $1(50)$ & 0 & 2 \\
\hline Total & $109(29.47)$ & $184(47.96)$ & $44(24.90)$ & $18(6.71)$ & 358 \\
\hline
\end{tabular}

\section{DISCUSSION}

Transfusion transmitted diseases have an increased significance worldwide because they contribute towards the spread of infectious diseases to the population while proper screening of donors can considerably reduce the possibility of transmission. ${ }^{6}$ In the developing countries, along with various other factors, poor socioeconomic conditions favor the prevalence of infectious diseases among population such as Hepatitis B, Hepatitis C and HIV. The present study was aimed to determine the frequency of HBV, HCV, HIV, TP and MP among blood units donated at Khulna Medical College Hospital, Khulna during the study period spanning from January 2015 to December 2016.

The majority of the donors in the present study were males (94.14\%) with a small percentage $(5.86 \%)$ of female donors (Table 1). This is comparable to the studies done by Prakash et $\mathrm{al}^{5}$. Pahuja et al. ${ }^{7}$ Karmakar PR et al. ${ }^{8}$ and Shrestha AC et al. ${ }^{9}$ noting more than $90 \%$ of the male donors. Similarly, male dominated donor pool was reported by the studies done in South-East Nigeria by Okacha ${ }^{10}$ and in Tanzania by Matee $^{11}$. They also recorded the higher prevalence of all TTIs in male donors than females. In contrast, a study in China showed higher rate of female donors (44.5\%) which was attributed to increased knowledge regarding the blood donation $^{12}$.

The prevalence of HBV, HCV, syphilis and HIV in the present study was $0.72 \%, 0.03 \%, 0.2 \%$ and $0.01 \%$ respectively (Table II). In Bangladesh, a study was conducted by Ara $\mathrm{F}$ et.al ${ }^{13}$ showed prevalence of $\mathrm{HBV}$, HCV, HIV, and syphilis were 0.009, 0.0004, 0.0001 and
$0.0001 \%$ respectively which is low in comparison with present study. Another study was conducted byAra F et .al ${ }^{14}$ the Prevalence of hepatitis B virus (HBV), HCV, and syphilis were $1.20,0.68$ and $0.34 \%$ respectively which is similar to present study.

Another study was conducted in Bangladesh by Saha SK et . $\mathrm{a}^{15}$ the Prevalence of hepatitis B virus (HBV), HCV, HIV and syphilis were $2.19 \%, 0.25 \%, 0.06 \%$ and $0.15 \%$.

At Mysuru, India, a study was conducted by Prakash $\mathrm{P}$ et.al ${ }^{16}$ reported the prevalence of $\mathrm{HBV}, \mathrm{HCV}$, syphilis and HIV was $0.96 \%, 0.13 \%, 0.15 \%$ and $0.26 \%$, respectively.

The overall seroprevalence of TTIs in the present study was $0.96 \%$ which is comparable to the study done in Mangalore, Karnataka by Lathamani et al. reporting TTIs of $0.82 \%{ }^{17}$.

Howerver, the seroprevalence in thepresent study is low when compared to the studies done by Chaurasia et al. and Karmakar et al. noting $2.5 \%$ and $2.79 \%$ respectively ${ }^{18,19}$. High prevalence rate of $15.9 \%$ and $20.09 \%$ was observed in African countries of Tanzania and Nigeria ${ }^{20,21}$. This variation in magnitude of TTIs from country to country depends on loads in that particular population. This could also be due to study site lacking sensitive donor screening program, public awareness and education so that infected persons can self-select themselves and opt out from donating blood due to problem of asymptotic carriers, window period, and false negative tests ${ }^{19}$.

In the present study, the seropositivity was high (47.96\%) among the age group of 26-35 years and a small fraction $6.71 \%$ were in the age category of $46-55$ years. The $18-25$ 
years age group showed the second highest clustering of TTIs with $29.47 \%$ positive rates (Table III).

In India, a study was conducted the seropositivity was high (43.35\%) among the age group of 26-35 years and a small fraction $10.80 \%$ were in the age category of $46-55$ years. The 18-25 years' age group showed the second highest clustering of TTIs with $27.60 \%$ positive rates 5

In our country, majority of the donors belongs to 18-35 age group. Among them seropositivity is high in 25-35 years. From this study, it may be suggested that if we recruitedmore donors form younger age group (18-25 yrs.) and counselled them about route of transmission of STI and vaccinated them in seronegative donors of $\mathrm{HBV}$, reduce the significant rise of TTI among them, who ultimately comprise 26-35 years' age group in near future.

The sero-prevalence of TTIs in the present study was highest for HBV infection $(0.72 \%)$. A study was conducted by Ara F et.al ${ }^{13}$, atNational Institute of Neurosciences (NINS) and Hospital in Dhaka, Bangladesh,the prevalence of HBsAg was $1.196 \%$. In Bangladesh another study was conducted by Saha SK et $\mathrm{al}^{15}$ the prevalence of HBV was $2.19 \%$. In India, comparable sero-prevalence of $\mathrm{HBsAg}$ was noted by Prakashet al $(0.99 \%)^{5}$, Giri et al. $(1.09 \%)^{1}$ and Chattoraj et al. $(0.99 \%)^{21}$.

In our study, seropositivity of HCV and HIV was low ( $0.03 \%$ and $0.01 \%$ respectively). This value was much lower than other studies conducted in Bangladesh 2,14,15. In India, the seroprevalence of $\mathrm{HCV}$ is relatively high in comparison to our study $1,{ }^{5,21}$. The worldwide prevalence ofhepatitis C virus infection is estimated by the World Health Organization (WHO) to be approximately 3\% corresponding to $130-150$ million infected persons ${ }^{22}$. The highest prevalence $(28 \%)$ of $\mathrm{HCV}$ has been reported in Egypt $^{22}$.

The seropositivity for syphilis in the present study was $0.20 \%$ which is second highest in this study. A study conducted by Saha K et.al.in Bangladesh, the reactivity of VDRL varied from 0.09 to $0.23 \%$. Another study done by Ara F et.al.the VDRL reactivity was $0.341 \%{ }^{14}$.

Similar findings were noted by Prokash et.al. $(0.15 \%)^{16}$ and Karmarkar et al. $(0.23 \%)^{19}$.

The World Health Organization estimated that approximately 6 million new cases of syphilis are reported each year in the world. ${ }^{23}$ So, the reason for high prevalence of syphilis in our study might be due to more numbers of replacement donors and improved detection methods.
Syphilis is detected in significantly high number among healthy donors. So most sensitive methods should be adopted to screen syphilis. More studies are needed to find the prevalence of syphilis in public sector hospitals.

In the present study there was no positive cases found for malarial parasite.Malaria is estimated to be directly responsible for around one million deaths annually worldwide ${ }^{26}$. The number of malaria cases in Bangladesh fluctuates seasonally. The majority of these cases occur in the thirteen districts close to and/or bordering India and Myanmar. These thirteen districts, out of the 64 administrative districts of Bangladesh, are recognized as malaria endemic. Ninety-eight percent of the malaria case reports come from these thirteen districts. Three out of these thirteen districts, Bandarban, Khagrachari and Rangamati, collectively known as the Chittagong Hill Tracts (CHT) districts, report the highest incidence of malaria within the country ${ }^{24}$. Khulna is not enlisted of these thirteen districts for malaria.

Zero prevalence rates for malaria amongthe donor set in this study may be due to the fact that infection with malarial parasite results in development of fever and weakness. Because of the prominent signs and symptoms majority of the infected persons will not visit the blood donation Centre and even if theycome, will be readily excluded by medical fitness examination and counselling ${ }^{3}$. In Bangladesh two study reported by Ara F et al. and Saha SK et al. have also not found any of the donors positive for malaria ${ }^{13,15}$.

The greatest threat to the safety of the blood supply is the donation of blood by seronegative donors during the infectious window period when the donors are undergoing seroconversion. Such people represent new, or incident infections. Although new techniques of testing will bring us closer to the goal of zero risk, it is unlikely that any test or combination of tests will be cent percent effective in detecting window-period infections. It is also important to recognize that new, direct viral-detection tests will supplement existing screening assays rather than replace them ${ }^{25}$. A considerable portion of this improvement is due to the introduction of nucleic acid testing (NAT), rather than relying solely on measuring pathogen-specific humoral immune responses in the donor. This will decrease the window period and hence decrease the incidence of TTI. But the cost-effectiveness of NAT is poor. The NAT has added benefits but its high financial cost is of concern, especially in economically restricted countries ${ }^{18}$. Currently, no technology exists to completely detect all window period donations. No matter how sensitive NAT becomes, we will 
never be able to completely close the exposure-to-seroconversion window period. The general public and media might believe that with the advancement in testing technologies zero risk blood products are currently available. This generalization is far from reality as judged by our current experience with new testing methodologies ${ }^{18}$.

Serosurveys are one of the primary methods to determine the prevalence of TTIs because blood safety in very important especially in patients requiring regular blood transfusion such as those with sickle cell disease especially thalassemia, haematological malignanacies, and dialysis patients. Various studies have shown that high rate of transfusion transmissible viral infections in such high risk patients. Hence, the assessment helps in determining the safety of blood products and also gives an idea of the epidemiology of these diseases in the community.

There is a need for increased awareness for safe blood which can be obtained by motivating young donors. Also, implementation of strict donor selection criteria, use of sensitive screening tests and establishment of strict guidelines for bloodtransfusion are highly recommended to reduce the incidence of TTI and ensure the safety ofblood for recipient.

\section{REFERENCES:}

1. Giri PA, Deshpande JD, Phalke DB, Karle LB. Seroprevalence of transfusion transmissible infections among voluntary blood donors at a tertiary care teaching hospital in rural area of India. J Family Med Prim Care. 2012;1(1):48-51.

2. Islam MB. Blood transfusion services in Bangladesh. Asian J Transfus Sci. 2009; 3(2): 108-110

3. Raut MM, Joge US, Choudhari SG, et al. Seroprevalence of transfusion transmitted infections among healthy blood donors at blood bank attached to a tertiary care hospital in Maharashtra state of India. IJHSR. 2012;2(4):18-24.

4. Chaurasia R, Zaman S, Das B, Chatterjee K. Screening donated blood for transfusion transmitted infections by serology along with NAT and response rate to notification of reactive results: An Indian experience. J Blood Transfuse. 2014; 412105 .

5. Prakash P, Bobati SS and Basavaraj V. Prevalence of Transfusion Transmissible Infections among Blood Donors in a Tertiary Care Hospital of Mysuru District - A Six Years Study. IJTDH, 2016; 16(3): 1-8.

6. Arora D, Arora B, Khetarpal A (2010). Seroprevalence of HIV, HBV, HCV and syphilis in blood donors in Southern
Haryana. Indian J. Pathol. Microbiol. 53(2): 308

7. Pahuja S, Sharma M, Baitha B, Jain M. Prevalence and trends of markers of hepatitis $C$ virus, hepatitis $B$ virus and human immunodeficiency virus in Delhi blood donors: A hospital based study. Jpn J Infect Dis. 2007;60(6):389-91.

8. Karmakar PR, Shrivastava P, Ray TG. Seroprevalence of transfusion transmissible infections among blood donors at the blood bank of a medical college of Kolkata. Indian Journal of Public Health. 2014;58(1):61-64

9. Shrestha AC, Ghimre P, Tiwari BR, Rajkarnikar M. Transfusion-transmissible infections among blood donors in Kathmandu, Nepal. J Infect Dev Ctries. 2009;3(10):794-97.

10. Okocha EC, Aneke JC, Ezeh TU, Ibeh NC, Nwosu GA, Okorie IO, et al. The epidemiology of transfusiontransmissible infections among blood donors in Nnewi, South-East Nigeria. African J Med Health Sci. 2015;14:125-129.

11. Matee MI, Magesa PM, Lyamuya EF. Seroprevalence of human immunedeficiency virus, hepatitis B and C virusesand syphilis infections among blood donors at the Muhimbili National Hospital in Dar es Salaam, Tanzania. BMC Public Health. 2006;6:21.

12. Sunderam S, Karir S, Haider S, Singh SB, Kiran A. Sero-prevalence of transfusion transmitted infections among blood donors at blood bank of Rajendra institute of medical sciences, Ranchi. Healthline Journal. 2015;6:36-40.

13. Ara F, Alam ABMM, Rahman M, Jahan A, Yusuf MA, Hassan MS, Sonia SF, Nasreen Z,Biswas J. Prevalence of Transfusion Transmitted Infection among Blood Donors at Medical University in Bangladesh. J Shaheed Suhrawardy Med Coll, June 2014, Vol.6, No.1

14. Ara F, Nasreen Z, Islam MA, Yusuf MA,Hassan MS, Sonia SF, Frequency of Transfusion Transmitted Infection Among Blood Donors at Specialized Tertiary Care Hospital in Bangladesh.J. Natl Inst. Neurosci Bangladesh 2015;1(1):12-14

15. Shaha SK, Banik RK, Saha MR, Habibullah MM, Mahtab MA.Prevalence of Transfusion Transmitted Infection in Healthy Blood Donors in Sir Salimullah Medical College, Dhaka, Bangladesh. Euroasian Journal of Hepato-Gastroenterology 2011; 1: 68-70.

16. Pallavi Prakash, Shreedevi S. Bobati and Vijaya Basavaraj. Prevalence of Transfusion Transmissible Infections among Blood Donors in a Tertiary Care Hospital of Mysuru District - A Six Years Study.International Journal 
of tropical disease\& health2016;3: 1-8.

17. Latamani K, Bhaktha G, Nayak S, Kotigadde S. Prevalence of HIV, HCV, HBV and syphilis in blood donors among the Dakshina Kannada District, India. Int J Curr Microbiol Appl Sci. 2013:2(10):249- 252.

18. Chaurasia R, Zaman S, Das B, Chatterjee K. Screening donated blood for transfusion transmitted infections by serology along with NAT and response rate to notification of reactive results: An Indian experience.J Blood Transfus. 2014; 2014: 412105. Available from: http://dx.doi.org/10.1155/2014/412105. Accessed 16th August, 2017

19. Karmakar PR, Shrivastava P, Ray TG. Seroprevalence of transfusion transmissible infections among blood donors at the blood bank of a medical college of Kolkata. Indian Journal of Public Health. 2014;58(1):61-64.

20. Okocha EC, Aneke JC, Ezeh TU, Ibeh NC, Nwosu GA, Okorie IO, et al. The epidemiology of transfusion transmissible infections among blood donors in Nnewi, South-East Nigeria. African J Med Health Sci. 2015;14:125-129.

21. Chattoraj A, Bhel R, Kataria V. Infectious disease markers in blood donors. Med J Armed Forces India. 2008;64(1):33-5.

22. Armstrong G, Alter M, McQuillan et.al. The past infection of hepatitis $\mathrm{c}$ virus infection, implication of future burden of chronic liver disease I United states. Hematol 2000;31:777-82.

23. Newman L, Rowley J, Vander Hoorn S, Wijesooriya NS, Unemo M, Low N, et al. Global Estimates of the Prevalence and Incidence of Four Curable Sexually Transmitted Infections in 2012 Based on Systematic Review and Global Reporting. PLoS ONE 2015; 10(12): e0143304.

24. Haque U, Ahmed SM, Hossain S, Huda M,Hossain M and Alam MS et.al.Malaria Prevalence in Endemic Districts of Bangladesh.PLoS ONE 2009;4(8):e6737.

25. Shyamala V. Factors in enhancing blood safety by nucleic acid technology testing for human immShyamala $\mathrm{V}$. Factors in enhancing blood safety by nucleic acid technology testing for human immunodeficiency virus, hepatitis $\mathrm{C}$ virus and hepatitis B virus. Asian J Transfus Sci. 2015;8(1):13-18.

26. Greenwood BM, Boding K, Witty CJM, Target GA. Malaria. Lancet. 2005;365:1487-1498. 